\title{
Awareness of Preconception Care and Its Related Factors Among Women of Childbearing Age with Type I Diabetes in the South of Saudi Arabia: A Cross-Sectional Survey Study
}

Mohammed Jeraiby

Department of Biochemistry, Faculty of Medicine, Jazan University, Jazan, Saudi Arabia
Correspondence: Mohammed Jeraiby Department of Biochemistry, Faculty of Medicine, Jazan University, P.O. Box: 2349. Jazan, 82621, Saudi Arabia

Tel +966544589494

Email mojer20II@hotmail.com;

mmojer@jazanu.edu.sa
Background: Pregnancies in women with type 1 diabetes mellitus (T1DM) are associated with an increased risk of poor outcomes for mothers and their infants.

Objective: To assess the awareness of preconception care among women with T1DM and their self-management status in the southern region of Saudi Arabia.

Methods: This study is a cross-sectional study that was done on 187 women participated of childbearing age with T1DM who were seen in diabetic centers between June 2019 and September 2020. Pre-pregnancy care and disease management were assessed via a questionnaire.

Results: The prevalence of preconception awareness of diabetes management was $66.9 \%$. Several factors significantly influenced the level of awareness, including education level $(P=$ $0.001)$ and $\mathrm{HbA1c}(P=0.014)$. In multivariate analysis, the lower educational level turns out to be a significant risk factor for low awareness ( $\mathrm{OR}=3.71,95 \% \mathrm{CI}[1.65,8.31], P=0.001)$. Additionally, compared to controlled DM, uncontrolled diabetes had a twofold increased risk of low awareness (OR $=2.03,95 \%$ CI $[1.08,3.81], P=0.027)$.

Conclusion: The awareness level was significantly correlated with a high educational level and better glycemic control. Meanwhile, it was not significantly correlated with diabetes duration.

Keywords: T1DM, preconception care, awareness rate, women of childbearing age and self monitoring blood glucose

\section{Introduction}

Pregnancies in women with type 1 diabetes mellitus (T1DM) are associated with an increased risk of poor outcomes for the mothers and their infants. ${ }^{1,2}$ Before the existence of insulin therapy, infertility was the most common consequence of diabetes mellitus (DM) for reproductive-age women, and when pregnancy did occur, fetal and neonatal mortality rates were high. ${ }^{3}$ Compared to women without diabetes, women with T1DM have a poorer health prognosis and higher associated rates of congenital malformations, preeclampsia, premature delivery, perinatal mortality, and macrosomic babies. ${ }^{4}$ The important factors that aggravate T1DM and affect pregnancy outcomes mainly include poor blood glucose control, lack of pre-pregnancy awareness, and lack of effective disease management during pregnancy. ${ }^{5}$ Some studies have found that the risk of adverse outcomes (eg, 
malformation and perinatal mortality) is related to poor glycemic control during early pregnancy. ${ }^{6}$ The crucial time for favorable glycemic control is before the seventh week of gestation, during early organogenesis. ${ }^{7}$ However, a study found that hyperglycemia before pregnancy was also associated with a higher risk of multiple adverse pregnancy outcomes. ${ }^{8}$ These adverse outcomes can be avoided by optimizing the health of women with T1DM during the preconception period. Preconception care is a relatively new concept introduced by Chamberlain in 1980. ${ }^{9}$ Preconception diabetes counseling is defined as educating and discussing pregnancy and contraception with women of reproductive age, aimed at identifying and modifying biomedical, behavioral, and social risks to a woman's health or pregnancy outcome through prevention and management and it should be delivered annually in primary and/or specialist care to all women of reproductive age..$^{10,11}$ The most important aspect of preconception care is glycemic control, which has been associated with improvements in maternal and perinatal outcomes. $^{12,13}$ The guideline recommended for the management of preconception women with T1DM is to have glycated hemoglobin A1C (A1C) greater than 7\% and as close to $6 \%$ as possible without noticeable hypoglycemia. ${ }^{14}$ Many plans have been made to set up preconception care for women with T1DM in order to reduce health risks for mothers and fetuses. ${ }^{15-17}$ Studies in Ireland have shown that effective preconception management can significantly reduce the risk of adverse pregnancy outcomes in women with T1DM. ${ }^{18}$ Therefore, women of childbearing age with T1DM should be counseled about the pregnancy risks associated with DM to ensure that pregnancies are planned and that awareness and self-management increase. The aim of this study was to assess the awareness of preconception care among women with (T1DM) and their self-management status in order to provide evidence for the development of management pathway for women with T1DM during pregnancy in the southern region of Saudi Arabia.

\section{Materials and Methods}

A simple random sampling was used: female T1DM patients who resided in the southern region of Saudi Arabia between June 2019 and September 2020 had a clear diagnosis of T1DM for at least 1 year, and were age 18 years or older at the time of survey were eligible for inclusion in the study. Women who were pregnant at the time of interview had used insulin for less than 4 months, and refused to participate were excluded. Ethical considerations were followed in agreement with the Declaration of Helsinki throughout this study, and it was approved by the Research Committee/IRB Jazan, Kingdom of Saudi Arabia (Reference No. 2004). Participants reviewed and agreed to a sign of informed consent.

This study used a published questionnaire that included 20 questions split into 2 sections. ${ }^{19}$

The first section covered demographic information, such as age of onset, education level, marital status, living situation, and income level. The second section was devoted to assessing pre-pregnancy and disease management for T1DM women planning pregnancy and their related conditions, such as insulin treatment plan, A1C, frequency of self-monitoring blood glucose (SMBG), and diabetes education. ${ }^{19}$ The Cronbach's alpha value of the questionnaires was 0.80 , which reflected good reliability.

The main evaluation covered standardized insulin injection technology; hypoglycemia symptoms and interventions; clinical manifestations of diabetes; complications of diabetes; prevention and treatment of acute and chronic complications, especially the feet; nursing; individualized treatment goals; regular exercise; individualized lifestyle interventions and diet plans; oral medication; and insulin therapy. ${ }^{20,21}$ Diabetes education was delivered to patients by a dietitian and diabetologist. Insulin treatment programs are divided into insulin pumps, continuous subcutaneous insulin injections (CSII) and multiple daily insulin injections (MDI) defined as daily subcutaneous insulin injections 4 or more times per day.

Data were analyzed by using the Statistical Package for Social Studies (SPSS 22; IBM Corp., New York, NY, USA). The continuous variables were expressed as mean \pm standard deviation, and categorical variables were expressed as percentages. The $t$-test and one-way ANOVA were used for continuous variables. Cronbach's alpha was used to assess reliability and internal consistency of the items in the questionnaire. Univariate logistic regression was used to assess factors associated with low levels of awareness. Each correct response was given a score of 1 , and each woman was scored out of a total of 13. A score of less than 6.5 was considered poor, 6.5 to 9.75 was considered good, and greater than 9.75 was considered excellent awareness of diabetes and pregnancy. A $p$-value less than 0.05 was considered statistically significant. 
Table I Sociodemographic Characteristics of the Study Participants (Saudi Females of Childbearing Age with TIDM)

\begin{tabular}{|l|l|c|c|}
\hline & & Number & $\%$ \\
\hline Marital Status & Married & 74 & 39.8 \\
& Single & 108 & 58.1 \\
& Divorced & 4 & 2.2 \\
\hline Living Alone & Yes & 9 & 4.8 \\
& No & 177 & 95.2 \\
\hline Income & Low & 34 & 18.4 \\
& Moderate & 137 & 74.1 \\
& High & 14 & 7.6 \\
\hline Education Level & Primary and less & 11 & 5.9 \\
& Secondary and & 35 & 18.9 \\
& intermediate & & \\
& University and above & 139 & 75.1 \\
\hline Insulin Planning & Insulin pump & 46 & 25.8 \\
& Insulin injection & 132 & 74.2 \\
\hline Duration of DM & & 13.59 & 9.75 \\
(Mean \pm SD) & $<5 y$ & 28 & 15.9 \\
& $5-10 y$ & 51 & 29.0 \\
& $>10 y$ & 97 & 55.1 \\
\hline \multirow{2}{*}{ AIC (Mean \pm SD) } & & 7.86 & 2.07 \\
& $<7$ & 65 & 36.7 \\
& & 112 & 63.3 \\
\hline
\end{tabular}

\section{Results}

A total of 187 female Saudi T1DM patients participated in the current study: more than half (58.1\%) were single, while $39.8 \%$ were married (see Table 1). Some patients are missing in each of the items analyzed, 1 in marital status and in Living alone, 2 missing in income and education level, 9 are missing in insulin planning and in $\mathrm{A} 1 \mathrm{C}$, and 11 missing from duration of DM.

Almost three-quarters (74.1\%) had a moderate-income level and university education (75.1\%). More than half (55.1\%) had dealt with the disease for longer than 10 years. The mean A1C was $7.86( \pm 2.07) ; 63.3 \%$ of participants had greater than or equal to $7 \%$.

Overall, the total mean $( \pm \mathrm{SD})$ score of the awareness questions was $8.70( \pm 3.02)$ out of 13 , indicating acceptable awareness levels. The results revealed that the highest awareness level was for the question "Do you think that it is necessary to strengthen blood glucose monitoring during pregnancy?" It was correctly answered by $91.4 \%$ of participants, with a mean of $0.91( \pm 0.28)$. The next highest question was "Do you think that blood glucose monitoring during pregnancy must cover every meal?" It was correctly answered by $85 \%$ of participants, with a mean score of 0.85 $( \pm 0.36)$. This was followed by "Without contraindications, 30 minutes of low to moderate exercise per day is required." It was correctly answered by $81.3 \%$ of participants, with a mean score of $0.81( \pm 0.39$; see Table 2$)$.

Almost $37 \%$ of participants thought that T1DM patients cannot get pregnant; when participants were asked to explain why, about one-quarter (25.1\%) said that diabetic pregnancy is dangerous for both the mother and the fetus.

The lowest awareness level was for the question "Do you think that it is necessary to have a diabetic fundus examination before pregnancy?" Only 33.7\% of participants answered correctly with "Yes," and the mean score was $0.34( \pm 0.47)$. Also, less than half $(48.7 \%)$ knew the multivitamin supplements that need to be supplemented with folic acid before pregnancy (see Table 2).

There was no significant difference in the total mean score of awareness by marital status $(P=0.178)$; however, the score was highest among divorced participants, at 11.25 $( \pm 1.50)$. Similarly, the awareness score did not differ significantly by income level or living status (all $P>0.05$ ). Highincome females showed the highest score at $9.21( \pm 1.76)$. Those living alone scored $10.11( \pm 2.80)$, and those living with others scored $8.68( \pm 2.95)$. Additionally, the awareness score was higher among insulin injectors (DMI) than pump users (CSII): $8.74( \pm 2.75)$ and $8.50( \pm 3.71)$, respectively $(P=$ 0.686 ). Awareness level was not significantly correlated with diabetes duration but was highest among the group with 5 to 10 years duration: $9.65( \pm 2.02 ; P=0.072)$.

In contrast, awareness level was significantly associated with education level and A1C level. There was a positive correlation between education level and awareness level, as awareness increased gradually with increases in education level: $7.36( \pm 3.85), 7.40( \pm 3.08)$, and $9.26( \pm 2.62)$ for primary and less, secondary and intermediate, and university and above, respectively $(P=0.001)$. Similarly, the association was positive between awareness level and diabetes control; participants with A1C level less than 7\% showed a significantly higher awareness level at $9.57( \pm 2.47)$ compared to $8.47( \pm 3.02)$ for those with $\mathrm{A} 1 \mathrm{C}$ greater than or equal to $7 \%$ with a $p$-value of 0.014 (see Table 3).

The results revealed that intermediate and secondary education levels were a significant risk factor for low awareness, with a more than threefold ( $\mathrm{OR}=3.71,5 \%$ CI $[1.65,8.31], P=0.001)$ increase in the risk of low awareness of preconception management. Additionally, compared to controlled DM, uncontrolled diabetes had 
Table 2 Mean and Standard Deviation for the Items on the Questionnaire and Percentages of Correct Answers of Preconception Care Awareness for Females of Childbearing Age with TIDM

\begin{tabular}{|c|c|c|c|c|c|}
\hline Items & Mean & SD & Median & Number & $\%$ \\
\hline Do you think that patients with type I or type 2 diabetes can get pregnant? & 0.63 & 0.48 & 1.00 & 118 & 63.1 \\
\hline If you feel unable to get pregnant, what is the reason? & 0.26 & 0.44 & 0.00 & 48 & 25.7 \\
\hline How much glycated hemoglobin do you think can be pregnant before pregnancy? & 0.72 & 0.45 & 1.00 & 134 & 71.7 \\
\hline $\begin{array}{l}\text { Do you know the multivitamin supplements that need to be supplemented with folic acid before } \\
\text { pregnancy? }\end{array}$ & 0.49 & 0.50 & 0.00 & 91 & 48.7 \\
\hline Do you think that it is necessary to strengthen blood glucose monitoring during pregnancy? & 0.91 & 0.28 & 1.00 & 171 & 91.4 \\
\hline Do you think that blood glucose monitoring during pregnancy must cover every meal? & 0.85 & 0.36 & 1.00 & 159 & 85.0 \\
\hline Do you feel that blood and urine ketones must be monitored during pregnancy? & 0.79 & 0.41 & 1.00 & 148 & 79.1 \\
\hline Do you think that it is necessary to control weight gain during pregnancy to avoid gaining too fast? & 0.80 & 0.40 & 1.00 & 150 & 80.2 \\
\hline Do you think that you need to plan your childbirth in advance during the third trimester? & 0.56 & 0.50 & 1.00 & 105 & 56.1 \\
\hline Do you think that it is necessary to have a diabetic fundus examination before pregnancy? & 0.34 & 0.47 & 0.00 & 63 & 33.7 \\
\hline Do you think that it is necessary to screen for diabetic kidney complications before pregnancy? & 0.78 & 0.42 & 1.00 & 145 & 77.5 \\
\hline Without contraindications, 30 minutes of low to moderate exercise per day are required. & 0.81 & 0.39 & 1.00 & 152 & 81.3 \\
\hline Do you think that a thyroid function test is needed before pregnancy? & 0.76 & 0.43 & 1.00 & 143 & 76.5 \\
\hline Total Score (out of 13) & 8.70 & 3.02 & 10.00 & 187 & $66.9 \%$ \\
\hline
\end{tabular}

Table 3 Mean Total Scores of Preconception Management Awareness by Characteristics of the Patients

\begin{tabular}{|l|l|c|c|c|}
\hline & & Mean & SD & P value \\
\hline Marital Status & Married & 8.50 & 3.23 & 0.178 \\
& Single & 8.82 & 2.76 & \\
& Divorced & 11.25 & 1.50 & \\
\hline Living Alone & Yes & 10.11 & 2.80 & 0.157 \\
& No & 8.68 & 2.95 & \\
\hline Income & Low & 7.85 & 3.12 & 0.150 \\
& Moderate & 8.89 & 2.97 & \\
& High & 9.21 & 1.76 & \\
\hline Education & Primary and less & 7.36 & 3.85 & $0.001 *$ \\
Level & Secondary and & 7.40 & 3.08 & \\
& intermediate & & & \\
& University and above & 9.26 & 2.62 & \\
\hline Insulin & Insulin pump & 8.50 & 3.71 & 0.686 \\
Planning & Insulin injection & 8.74 & 2.75 & \\
\hline Duration of & $<5$ y & 8.36 & 3.70 & 0.072 \\
DM & $5-10 y$ & 9.65 & 2.02 & \\
& $>10 y$ & 8.64 & 2.93 & \\
\hline AIC & $<7$ & 9.57 & 2.47 & $0.014^{*}$ \\
& $\geq 7$ & 8.47 & 3.02 & \\
\hline
\end{tabular}

Note: *Significant $p$-value.

a twofold increased risk of low awareness $(\mathrm{OR}=2.03$, $95 \%$ CI $[1.08,3.81], P=0.027)$. Conversely, compared to participants with DM duration greater than or equal to 10 years, participants with DM duration of 5 to 10 years had a good awareness level $(\mathrm{OR}=0.49,95 \%$ CI $[0.24,0.99]$, $P=0.046$; see Table 4).

\section{Discussion}

To achieve proper quality of life and reduce the rate of adverse outcomes for pregnant women with T1DM, patients must take self-awareness of preconception diabetes status management and glycemic control into consideration. For this study, the preconception awareness rate of Saudi women of childbearing age with T1DM was good (66.9\%). Women with a high level of education (university and above) tended to have high awareness of preconception care. In contrast, a recently published study by Zheng et al reported that the preconception management awareness rate of women of childbearing age was low $20 \% .{ }^{19}$ Additionally, a British survey of pregnancy outcomes of preconception diabetes revealed that more than half of pregnant diabetic patients did not undergo preconception management. ${ }^{2}$ A retrospective study in Canada identified that only $36.2 \%$ of women with T1DM participated in preconception care. ${ }^{22}$ Therefore, increasing awareness is important for increasing the preconception management participation rate. The results showed that more than $63.3 \%$ of women of childbearing age with T1DM had poor blood glucose control (A1C $\geq 7 \%$ ). A similar study performed in China found that more than $70 \%$ of women of childbearing age with T1DM had poor blood glucose control. ${ }^{19}$ Although measurement of A1C remains the gold standard for assessing glycemic control and predicting the risk of complications, it has a number of 
Table 4 Univariate Logistic Regression for Low Awareness of Preconception Management and Related Factors

\begin{tabular}{|c|c|c|c|c|c|}
\hline & & \multirow[t]{2}{*}{ Odds Ratio } & \multicolumn{2}{|c|}{$95 \% \mathrm{Cl}$} & \multirow[t]{2}{*}{$p$-value } \\
\hline & & & Lower & Upper & \\
\hline Marital Status & $\begin{array}{l}\text { Married** } \\
\text { Single }\end{array}$ & $\begin{array}{l}1.00 \\
0.85\end{array}$ & 0.47 & 1.53 & 0.584 \\
\hline Living Alone & $\begin{array}{l}\text { Yes } \\
\text { No** }\end{array}$ & $\begin{array}{l}0.30 \\
1.00\end{array}$ & 0.06 & 1.46 & 0.135 \\
\hline Income & $\begin{array}{l}\text { Low } \\
\text { Moderate } \\
\text { High** }\end{array}$ & $\begin{array}{l}0.79 \\
0.43 \\
1.00\end{array}$ & $\begin{array}{l}0.22 \\
0.14\end{array}$ & $\begin{array}{l}2.88 \\
1.36\end{array}$ & $\begin{array}{l}0.725 \\
0.151\end{array}$ \\
\hline Education Level & $\begin{array}{l}\text { Primary and less } \\
\text { Secondary and intermediate } \\
\text { University and above** }\end{array}$ & $\begin{array}{l}2.59 \\
3.71 \\
1.00\end{array}$ & $\begin{array}{l}0.73 \\
1.65\end{array}$ & $\begin{array}{l}9.28 \\
8.31\end{array}$ & $\begin{array}{c}0.143 \\
0.001 *\end{array}$ \\
\hline Insulin Planning & $\begin{array}{l}\text { Insulin pump } \\
\text { Insulin injection** }\end{array}$ & $\begin{array}{l}0.79 \\
1.00\end{array}$ & 0.40 & 1.56 & 0.501 \\
\hline Duration of DM & $\begin{array}{l}<5 y \\
5-10 y \\
>10 y^{* *}\end{array}$ & $\begin{array}{l}0.68 \\
0.49 \\
1.00\end{array}$ & $\begin{array}{l}0.29 \\
0.24\end{array}$ & $\begin{array}{l}1.58 \\
0.99\end{array}$ & $\begin{array}{c}0.366 \\
0.0467^{*}\end{array}$ \\
\hline AIC & $\begin{array}{l}<7 * * \\
\geq 7\end{array}$ & $\begin{array}{l}1.00 \\
2.03\end{array}$ & 1.08 & 3.81 & $0.027^{*}$ \\
\hline
\end{tabular}

Notes: *Significant $p$-value. **Used as a reference.

limitations that make it less helpful for personalized diabetes management; it does not reflect rapid glycemic variation that may lead to acute events, such as hypoglycemia or postprandial hyperglycemia on a daily basis, which have been linked to complications. ${ }^{23-26}$ However, further investigation in this study revealed that $30.4 \%(57 / 187)$ of participants met the guideline for blood glucose monitoring ( $\geq 4$ times per day) and that $14.03 \%(8 / 57)$ used continuous glucose monitoring (CGM) systems (FreeStyle Libre 14-day CGM) that reported automatically every 5 minutes to a smartphone app such as Tomato or xDrip. Some participants used MiaoMiao Reader for FreeStyle Libre and received alarms for low or high blood glucose levels; this indicated when to administer high blood glucose correction doses or carbohydrate coverage doses. All diabetic centers in Saudi Arabia provide FreeStyle Libre for patients under age 12 in order to easily monitor daily variation, help parents monitor their children, and reduce needle checks for measuring blood glucose. These CGM systems can also report estimated A1C (e A1C) during a 14-day period, which may be helpful for ensuring safe and effective clinical management. ${ }^{27}$

The majority of participants with high levels of awareness used social media for gathering and sharing information about living with and managing diabetes and using technology to monitor and control the condition. Participants were able to meet experts and contact consultant endocrinologists and diabetologists through social media. This social media usage increased awareness and disseminated knowledge among other patients. ${ }^{28}$ Although the frequency of SMBG among study participants was acceptable, 11.3\% (21/187) had almost never used SMBG; such patients had low and intermediate education. A similar study in China found that $21.1 \%$ of patients had almost never used SMBG. ${ }^{19}$ There are certain limitations to this study. It is a singlecenter study including patients in Jazan alone. Therefore, this study is based on the patient's selfreport of previous medical treatment as the main criterion for receiving a corresponding diabetes education module. The survey results reflect the preconception management awareness rate and self-glycemic management effect of women of childbearing age in a nonpregnant state. Therefore, we hope to further improve the above-mentioned related surveys in the population survey and cohort studies to provide a basis for improving the pregnancy outcomes of women with type 1 diabetes in Saudi and formulating a management path for type 1 diabetes during pregnancy. 


\section{Conclusion}

In summary, Saudi type 1 diabetes mellitus females have a good knowledge level regarding preconception care. Such awareness level was significantly correlated with a high educational level and better glycemic control. Meanwhile, it was not significantly correlated with income level, living status, or diabetes duration.

\section{Author Contributions}

The author made a significant contribution to the work reported, whether that is in the conception, study design, execution, acquisition of data, analysis and interpretation, or in all these areas; took part in drafting, revising or critically reviewing the article; gave final approval of the version to be published; have agreed on the journal to which the article has been submitted; and agree to be accountable for all aspects of the work.

\section{Disclosure}

The author reports no conflicts of interest in this work.

\section{References}

1. Persson M, Norman M, Hanson U. Obstetric and perinatal outcomes in type 1 diabetic pregnancies: a large, population-based study. Diabetes Care. 2009;32(11):2005-2009. doi:10.2337/dc09-0656

2. Tennant PWG, Glinianaia SV, Bilous RW, Rankin J, Bell R. Preexisting diabetes, maternal glycated haemoglobin, and the risks of fetal and infant death: a population-based study. Diabetologia. 2014;57(2):285-294. doi:10.1007/s00125-013-3108-5

3. Kitzmiller JL. Preconception care of diabetes. Glycemic control prevents congenital anomalies. JAMA. 1991;265(6):731-736. doi:10.10 01/jama.265.6.731

4. Mills JL, Baker L, Goldman AS. Malformations in infants of diabetic mothers occur before the seventh gestational week. Implications for treatment. Diabetes. 1979;28(4):292-293. doi:10.2337/diabetes.28. 4.292

5. Fuhrmann K, Reiher H, Semmler K, Fischer F, Fischer M, Glockner E. Prevention of congenital malformations in infants of insulin-dependent diabetic mothers. Diabetes Care. 1983;6(3):219-223. doi:10.2337/ diacare.6.3.219

6. Wei $\mathrm{Y}, \mathrm{Xu} \mathrm{Q}$, Yang $\mathrm{H}$, et al. Preconception diabetes mellitus and adverse pregnancy outcomes in over 6.4 million women: a population-based cohort study in China. PLoS Med. 2019;16(10): e1002926. doi:10.1371/journal.pmed.1002926

7. Fuhrmann K, Reiher H, Semmler K, Glöckner E. The effect of intensified conventional insulin therapy before and during pregnancy on the malformation rate in offspring of diabetic mothers. Exp Clin Endocrinol. 1984;83(2):173-177. doi:10.1055/s-0029-1210327

8. Goldman JA, Dicker D, Feldberg D, Yeshaya A, Samuel N, Karp M. Pregnancy outcome in patients with insulin-dependent diabetes mellitus with preconceptional diabetic control: a comparative study. $\mathrm{Am}$ J Obstet Gynecol. 1986;155(2):293-297. doi:10.1016/0002-9378(86) 90812-4

9. Chamberlain G. The prepregnancy clinic. BMJ. 1980;281(6232): 29-30. doi:10.1136/bmj.281.6232.29
10. Johnson K, Posner SF, Janis Biermann JF, et al.; CDC/ATSDR Preconception Care Work Group, and Select Panel on Preconception Care. Recommendations to improve preconception health and health care-United States. A report of the CDC/ATSDR preconception care work group and the select panel on preconception care. MMWR Morb Mortal Wkly Rep. 2006;55(RR-6):1-23.

11. McCance DR. Pregnancy and diabetes. Best Pract Res Clin Endocrinol Metab. 2011;25(6):945-958. doi:10.1016/j.beem.20 11.07.009

12. Steel JM, Johnstone FD, Hepburn DA, Smith AF. Can prepregnancy care of diabetic women reduce the risk of abnormal babies? BMJ. 1990;301(6760):1070-1074. doi:10.1136/bmj.301.6760.1070

13. Rosenn B, Miodovnik M, Combs C, Khoury J, Siddiqi T. Preconception management of insulin-dependent diabetes: improvement of pregnancy outcome. Int $J$ Gynecol Obstet. 1992;38(1):70. doi:10.1016/0020-7292(92)90749-9

14. Jensen DM, Korsholm L, Ovesen P, et al. Peri-conceptional A1C and risk of serious adverse pregnancy outcome in 933 women with type 1 diabetes. Diabetes Care. 2009;32(6):1046-1048. doi:10.2337/dc082061

15. Overview | Diabetes in pregnancy: management from preconception to the postnatal period | Guidance | NICE. Available from: https:// www.nice.org.uk/guidance/ng3. Accessed July 8, 2021.

16. Gold AE, Reilly R, Little J, Walker JD. The effect of glycemic control in the pre-conception period and early pregnancy on birth weight in women with IDDM. Diabetes Care. 1998;21(4):535-538. doi:10.2337/diacare.21.4.535

17. McGrogan A, Snowball J, de Vries CS. Pregnancy losses in women with Type 1 or Type 2 diabetes in the UK: an investigation using primary care records. Diabet Med. 2014;31(3):357-365. doi:10.1111/ dme. 12332

18. Penney GC, Mair G, Pearson DWM. Outcomes of pregnancies in women with type 1 diabetes in Scotland: a national population-based study. BJOG. 2003;110(3):315-318. doi:10.1046/j.1471-0528.2003. 02067. X

19. Zheng XY, Yang DZ, Ai HY, et al. [Awareness of preconceptional care and its related factors in women of child-bearing age with type 1 diabetes]. Zhonghua Yi Xue Za Zhi. 2019;99(34):2654-2659. Chinese. doi:10.3760/cma.j.issn.0376-2491.2019.34.004

20. Deakin TA, Cade JE, Williams R, Greenwood DC. Structured patient education: the Diabetes X-PERT Programme makes a difference. Diabet Med. 2006;23(9):944-954. doi:10.1111/j.1464-5491.2006.01 906.x

21. DAFNE Study Group. Training in flexible, intensive insulin management to enable dietary freedom in people with type 1 diabetes: dose adjustment for normal eating (DAFNE) randomised controlled trial. BMJ. 2002;325(7367):746. doi:10.1136/bmj.325.7367.746

22. González-Romero S, González-Molero I, Fernández-Abellán M, et al. Continuous subcutaneous insulin infusion versus multiple daily injections in pregnant women with type 1 diabetes. Diabetes Technol Ther. 2010;12(4):263-269. doi:10.1089/dia.2009.0140

23. Kato N, Cui J, Kato M. Structured self-monitoring of blood glucose reduces glycated hemoglobin in insulin-treated diabetes. $J$ Diabetes Invest. 2013;4(5):450-453. doi:10.1111/jdi.12072

24. Kempf K, Kruse J, Martin S. ROSSO-in-Praxi follow-up: long-term effects of self-monitoring of blood glucose on weight, Hemoglobin A1c, and quality of life in patients with type 2 diabetes mellitus. Diabetes Technol Ther. 2012;14(1):59-64. doi:10.1089/dia.2011.0116

25. Sonne DP, Hemmingsen B. Comment on American Diabetes Association. Standards of Medical Care in Diabetes-2017. Diabetes Care 2017;40(Suppl.1): S1-S135. Diabetes Care. 2017;40 (7):e92-e93. doi:10.2337/dc17-0299

26. Nielsen LR, Ekbom P, Damm P, et al. HbA1c levels are significantly lower in early and late pregnancy. Diabetes Care. 2004;27 (5):1200-1201. doi:10.2337/diacare.27.5.1200 
27. Beck RW, Connor CG, Mullen DM, Wesley DM, Bergenstal RM The fallacy of average: how using $\mathrm{HbA}_{1 \mathrm{c}}$ alone to assess glycemic control can be misleading. Diabetes Care. 2017;40(8):994-999. doi: $10.2337 / \mathrm{dc} 17-0636$
28. Cooper A, Kar P. A new Dawn: the role of social media in diabetes education. J Diabetes Nurs. 2014;18:68-71.

\section{Publish your work in this journal}

The International Journal of General Medicine is an international, peer-reviewed open-access journal that focuses on general and internal medicine, pathogenesis, epidemiology, diagnosis, monitoring and treatment protocols. The journal is characterized by the rapid reporting of reviews, original research and clinical studies across all disease areas. The manuscript management system is completely online and includes a very quick and fair peer-review system, which is all easy to use. Visit http://www.dovepress.com/ testimonials.php to read real quotes from published authors.

Submit your manuscript here: https://www.dovepress.com/international-journal-of-general-medicine-journal 